\title{
Characterisation of environmental radioactive particles
}

\author{
L. Aldave de la Heras, G. Tamborini, E. Hrnecek and M. Betti \\ European Commission, Joint Research Centre, Institute for Transuranium Elements, \\ P.O. Box 2340, 76125 Karlsruhe, Germany
}

\begin{abstract}
Control samples produced as $1 \mu \mathrm{m}$ size uranium oxide particles are described for the calibration of the instrumental techniques when applied for the characterisation of environmental radioactive particles. The efficiency of nuclear track methods is demonstrated for the location of hot spots in swipe and environmental samples. Examples of the characterisation in terms of morphology, structure, elemental and isotopic composition of radioactive environmental particles detected in sediments and soil samples from different origin are illustrated. The characteristics of the particles are related with the source term and the release scenarios. Correlation between measurements of bulk samples and particies are given.
\end{abstract}

\section{INTRODUCTION}

Radionuclides can be introduced in the environment through a variety of systems and processes as gases, aerosols and particulate matter. In this context, particles exhibiting a very high activity are usually called "hot particles" or "radioactive particles". They may be produced in nuclear weapons tests, nuclear reactor xcidents and fires and can also be released in authorised discharges from reprocessing plants and dumped radioactive waste [1]. They can be formed by two processes: disintegration of the nuclear fuel bulk material or condensation of evaporated products. When radioactive particles are released into the environment, information on the size distribution pattern, radionuclide and matrix composition, morphology and structure is essential for assessing weathering and subsequent mobilisation and biological uptake of associated radionuclides. Particle characteristics will depend on particular source, scenario, dispersion processes and deposition conditions.

At the Institute for Transuranium Elements (ITU) research activities for the characterisation of radioactive environmental particles started in 1993, when after the Gulf War the capability to detect clandestine nuclear activity by the measurements of the radioactive particles found in environmental and swipes samples was recognised [2]. ITU developed methods based on Secondary Ion Mass Spectrometry SMS) and Scanning electron Microscopy (SEM) to locate and characterise radioactive microparticles for their chemical as well as isotopic composition [3-5]. For the location of the spots, methods based on nuclear tacks - $\alpha$-tracks, $\beta$-autoradiography and fission tracks - have been also developed and applied to environmental and swipe samples [6]. Moreover, due to the lack of reference radioactive microparticles with linown isotopic composition, a methodology has been developed for the production of control particles having a defined size and isotopic composition [7].

In this paper, the developed procedures and techniques and their applications to real cases are described. Examples of radioactive environmental particles detected in sediments and soil samples from different origin are presented and their characterisation in terms of morphology, structure, elemental and isotopic composition highlighted. The characteristics are related with the source term and the release scenarios. Correlation between bulk measurements and particles are given. 


\section{CONTROL RADIOACTIVE MICROPARTICLE}

In order to generate particles of defined isotopic composition, certified reference uranium oxide powder was used to obtain a solution for the aerosol generation. The parameters of the aerosol generator were set up to produce particle of micron dimension, namely $1 \mu \mathrm{m}$ [7]. The particles were further characterised by SEM for the morphology and SIMS for their isotopic composition. In Fig 1 the SEM image (a) along with the SMS one (b) and the ${ }^{235} \mathrm{U} /{ }^{238} \mathrm{U}$ isotopic ratios obtained by SIMS (c) for the different reference standards used for particle generation, are shown. As can be seen in Fig. 1c, the experimental isotopic ratios were in good agreement with expected ones.

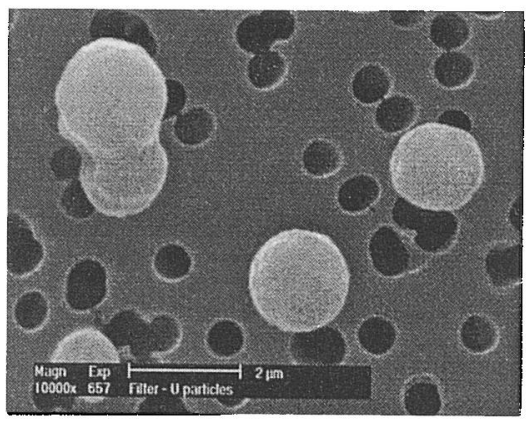

a)

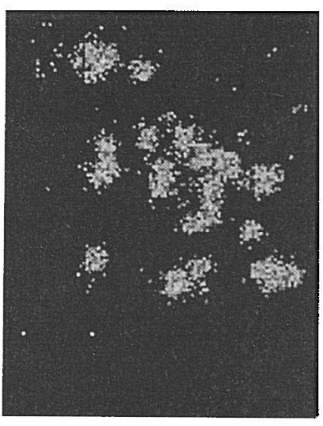

b)

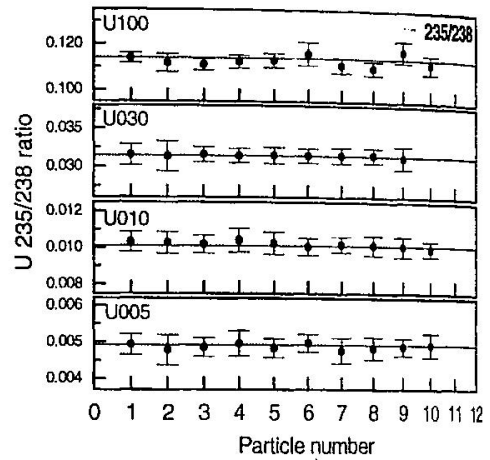

c)

Figure 1: SEM (a) and SIMS (b) images of the aerosol generated control particles. The isotopic ratios obtained by SIMS (c) are compared with expected reference values (line). In b) the bright color represents the maximum concentration in uranium.

\section{NUCLEAR TRACK METHODS APPLIED TO SWIPE AND ENVIRONMENTAL SAMPLES}

Nuclear tracks methods - $\alpha$-tracks, $\beta$-autoradiography and fission tracks - are very efficient for the detection of hot spots in environmental and swipe samples. The first two are spontaneously produced by the $\alpha$ - and $\beta$ emitting radionuclides in the samples. For fission tracks irradiation of the sample in a nuclear reactor is necessary. These methodologies can be very efficient for the identification of hot spots.

\begin{tabular}{|r|c|c|}
\hline$x(m \mathbf{m})$ & $\mathbf{y}(\mathbf{m} \mathbf{m})$ & Tracks \\
\hline 1,68 & 0,66 & $c a .25$ \\
\hline 3,45 & 2,08 & 20 \\
\hline 7,25 & 2,58 & 20 \\
\hline 8,29 & 2,18 & $10+20$ \\
\hline 10,21 & 2,20 & 14 \\
\hline 12,08 & 3,28 & ca. 30 \\
\hline 2,51 & 3,93 & 9 \\
\hline 10,45 & 3,65 & 17 \\
\hline 7,91 & 5,47 & 12 \\
\hline 15,59 & 5,24 & $c a .40$ \\
\hline 1,36 & 7,30 & 15 \\
\hline 0,59 & 7,24 & $c a .30$ \\
\hline 16,23 & 9,01 & 11 \\
\hline 14,55 & 8,55 & 12 \\
\hline 12,30 & 8,44 & 10 \\
\hline 7,73 & 9,12 & 27 \\
\hline 3,60 & 9,50 & 2100 \\
\hline 9,50 & 9,41 & 22 \\
\hline 14,34 & 9,43 & 30 \\
\hline
\end{tabular}

e)

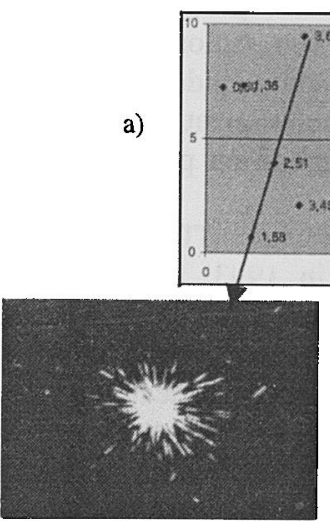

b)

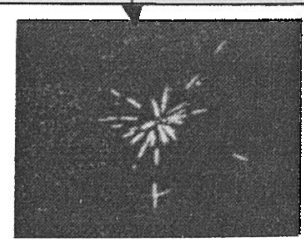

c)

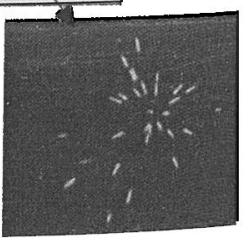

d)

Figure 2: Fission tracks obtained for particle containing uranium with a different enrichment in the isotope 235. A) Mapping of the particles obtained with optical microscopy after irradiation. Images of the tracks obtained from particles with different enrichment in U-235 (b, c, d), the relevant number of tracks are listed in table e). 
Figures $2 b$ ), c) and d) illustrate the tracks generated after irradiation in a nuclear reactor of particles containing uranium collected by swipe sampling. The number of tracks can be related to the enrichment in the isotope 235 of uranium. Therefore, hot spots due to not natural uranium can be easily detected, isolated and further investigated by SEM, SIMS or other mass spectrometric techniques, for instance thermal jonisation mass spectrometry.

The method based on the development of $\alpha$-tracks has been applied to detect hot spots in radioactively contaminated soil samples. An example is given in Fig. 3 where three different particles bearing ve-mitting radionuclides are evidenced.

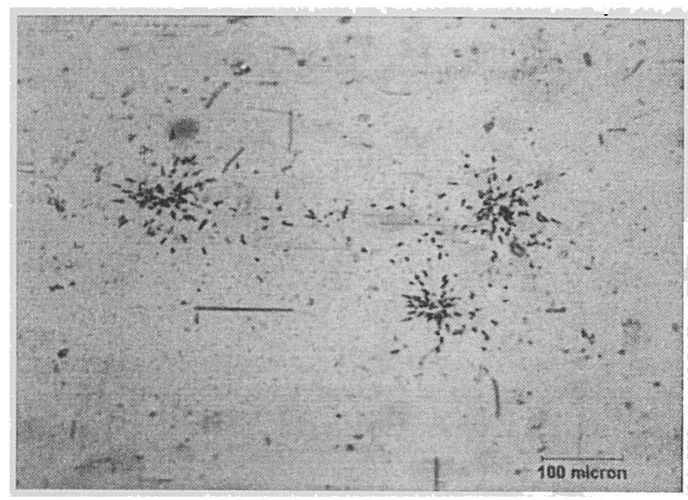

Figure 3: Identification of hot spots in a radioactively contaminated soil sample by development of $\alpha$-tracks.

\section{PARTICLES STEMMING FROM CHERNOBYL ACCIDENT}

Soil samples collected in the vicinity of the Chernobyl site were investigated. Radioactive particles containing uranium were located and isolated and further characterized by SEM and SIMS. In Figure 2a the SEM-EDX spectrum shows the line of uranium detected in the particle. The SIMS image of the same particle is illustrated in Figure $2 b$.

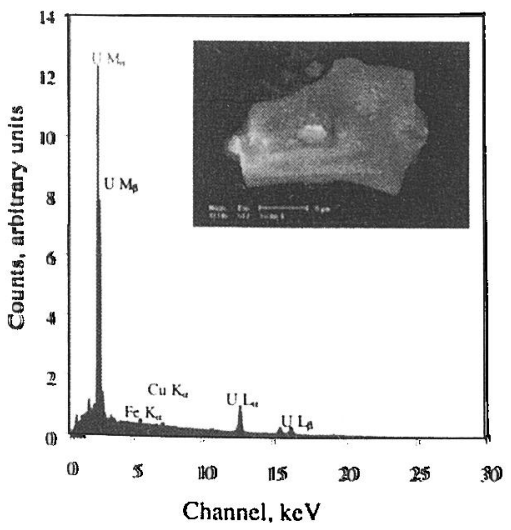

a)

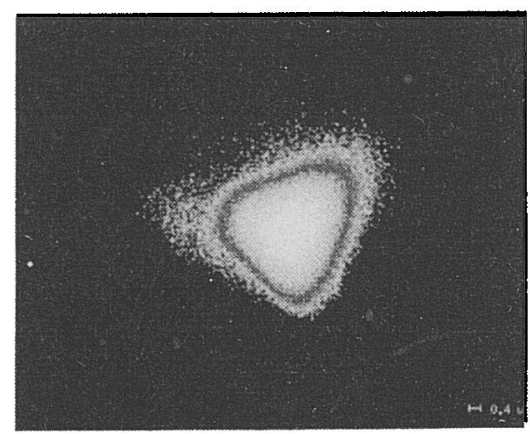

b)

Figure 4: a) SEM-EDX spectrum of a particle containing uranium; b) SIMS image of the particle. 
Several particles were analyzed and from the results of the two techniques it was found that all particles originated from nuclear fuel. The ratio ${ }^{235} \mathrm{U} /{ }^{238} \mathrm{U}$ was in the range $1.55-1.75$ atomic $\%$ in ${ }^{235} \mathrm{U}$, twice as high as the value of the natural uranium and corresponding to the enrichment of the fuel used in the Chernobyl reactor that was up to 1.8 atomic $\%$.

The particles consisted mostly of uranium oxide. In fact, small particles (often $<1 \mu \mathrm{m}$ ) were formed during the initial explosion of the reactor. Then, due to the high temperature reached, an evaporation process in the air took place and they were transformed in uranium oxide re-condensed in a glassy form. Their qualitative chemical composition was analyzed by SIMS and $\mathrm{C}, \mathrm{Al}, \mathrm{K}, \mathrm{Fe}, \mathrm{Mg}, \mathrm{Ca}$ and $\mathrm{Si}$ were detected. Fission products were also qualitatively observed on the surface of the particles.

\section{IRISH SEA SEDIMENTS}

A complete core of a sediment stemming from the Irish Sea was investigated by $\gamma$-spectrometry for the ${ }^{241} \mathrm{Am}$ concentration. The concentration profile in function of the depth is shown in Fig. 5a. In correspondence of the layer at $26-28 \mathrm{~cm}$ the highest concentration of ${ }^{241} \mathrm{Am}$ was found. This layer was then investigated by $\alpha$ tracks and a big (Fig 5b) and a small hot spot (Fig 5c) were obtained after two weeks of exposure time.

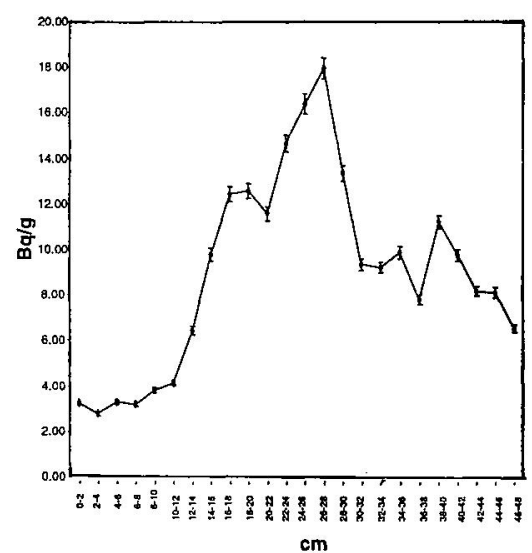

a)

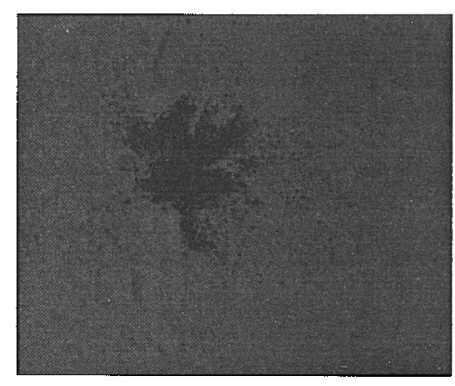

b)

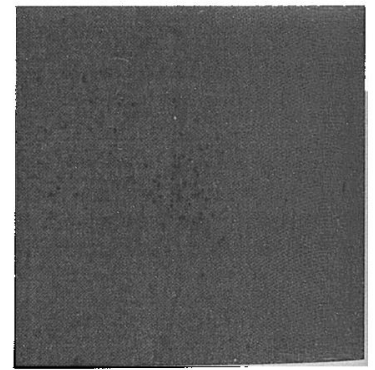

c)

Figure 5: a) ${ }^{241}$ Am concentration profile in function of depth for sediment core from the Irish Sea obtained by $\gamma$-spectrometry; b) and c) hot spots detected by $\alpha$-tracks for the layer at $26-28 \mathrm{~cm}$ depth after two weeks of exposure time.

The big hot spot was further investigated by SIMS. Uranium oxide particles with isotopic composition close to the natural one of uranium were detected. Moreover, small inclusions at mass 241 particles were also found, showed in Figure 6. The ion primary beam of the SIMS was also scanned as for the mass 239 and to 240 corresponding to plutonium isotopes, but no signals were detected. Therefore the inclusions at mass 241 can be attributed to ${ }^{241} \mathrm{Am}$, as confirming the results on the bulk sample obtained by $\psi$ spectrometry.

For the layer at $26-28 \mathrm{~cm}$ depth, measurements of the bulk sample as for uranium, plutonium and americium were performed by radiometric - liquid scintillation counting (LSC) and $\alpha$-spectrometry - as well by different mass spectrometric techniques - Inductively Coupled Plasma Mass Spectrometry (ICP-MS) and 


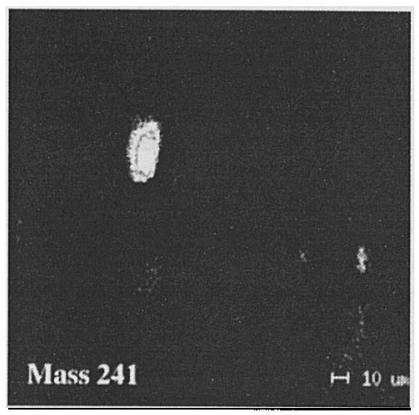

Figure 6: Inclusions detected at mass 241 by SIMS in the big hot spot of Fig. $5 \mathrm{~b}$.

Glow Discharge Mass Spectrometry (GDMS). The results obtained were found in good agreement as reported in table 1.

Table 1: Results obtained for the bulk sample at $26-28 \mathrm{~cm}$ depth by different radiometric and mass spectrometric techniques.

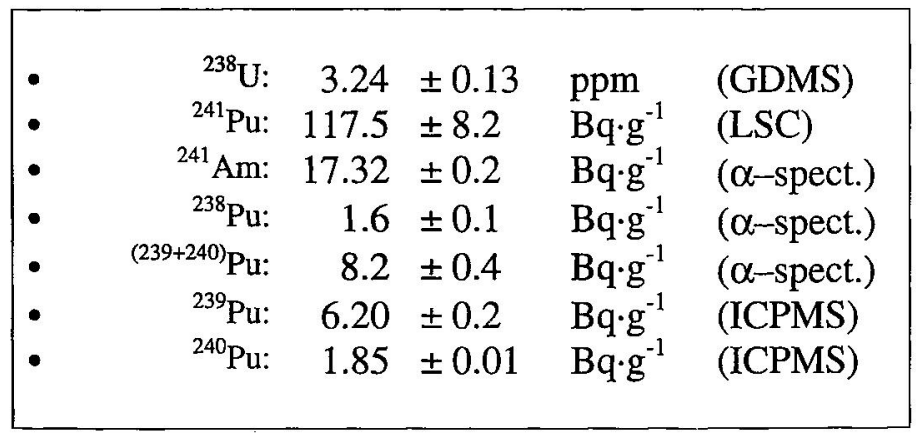

\section{CONCLUSIONS}

The characterization of particles is necessary in order to understand transport/diffusion mechanisms of radionuclides in environmental samples. Analysis of the bulk sample gives only an average information. Nevertheless can be applied for monitoring of environmental radioactivity provided that the presence of hot spots is taken in consideration. Methods based on nuclear tracks are very efficient for the location of radioactive particles and can applied to swipe and environmental samples. Once stated the presence of hot spots, they can be isolated and further investigated by SEM and SIMS.

\section{Acknowledgements}

The authors are grateful to F. Bocci for his help in editing of the paper. 


\section{References}

[1] Salbu, B., "Actinides associated with particles" Plutonium in the Environment, Osaka, Japan November 9-12, 1999, Ed. Kudo, A. (Elsevier, Amsterdam, 2001) pp.121-138.

[2] Donohue, D. and Ziesler, R., Anal. Chem. 65(7) (1993) 359A-368A

[3] Betti, M., Forcina, V., Hiernaut, T., Tamborini, G., and Koch, L., "Identification of nuclear activities by the characterization of single microparticles" IAEA International Symposium on International Safeguards, Vienna, Austria, 13-17 October 1997, IAEA-SM-351, pp. 316-321, 1997

[4] Tamborini, G., Betti, M., Forcina, V., Hiernaut, T., and Koch, L., Spectrochim. Acta, Part B 53 (1998) 1289-1302

[5] Betti, M., Tamborini, G., and Koch, L., Anal Chem 71 (1999) 2616-2622

[6] Tamborini, G., Betti, M., Carbol, P., and Koch, L., "Secondary Ion Mass Spectrometry for the detection of Radionuclides in Particles from soil samples", G.W.A. Newton (ed.), "Environmental Radiochemical Analysis", Royal Society of Chemistry, Cambridge, 1999, pp. 382-393

[7] Erdmann, N., Betti, M., Stetzer, O., Tamborini, G., Kratz, J. V., Trautmann, N., and van Geel, J Spectrochim. Acta Part B 55 (2000) 1565-1575 